\title{
The effectiveness of primary care based risk stratification for targeted latent tuberculosis infection screening in recent immigrants to the UK: a retrospective cohort study
}

\author{
Rakesh K Panchal, ${ }^{1}$ Ivan Browne, ${ }^{2}$ Philip Monk, ${ }^{3}$ Gerrit Woltmann, ${ }^{1}$ \\ Pranabashis Haldar ${ }^{4}$
}

${ }^{1}$ Department of Respiratory Medicine, Institute for Lung Health, Glenfield Hospital, Leicester, Leicestershire, UK ${ }^{2}$ Public Health, NHS Leicester City, New Walk Centre, Leicester, UK

${ }^{3}$ Public Health, Health Protection Agency, Leicester, UK

${ }^{4}$ Department of Infection, Immunity and Inflammation, University of Leicester, Respiratory Medicine, Glenfield Hospital, Leicester, UK

Correspondence to Dr Rakesh Panchal, Institute for Lung Health, Glenfield Hospital, Groby Road, Leicester LE3 9QP, UK; rakeshpanchal@doctors.org.uk

Received 5 June 2013 Revised 21 October 2013 Accepted 28 October 2013 Published Online First 19 November 2013
To cite: Panchal RK, Browne I, Monk $P$, et al. Thorax 2014;69:354-362.

\section{ABSTRACT}

Background Most UK tuberculosis (TB) cases occur in immigrants from high TB incidence areas, implicating reactivation of imported latent TB infection (LTBI). Strategies to identify and treat immigrant LTBI in primary care at the time of first registration (coded Flag-4) may be effective.

Methods This was an 11-year retrospective cohort study to evaluate effectiveness of LTBI screening in recent immigrants to Leicestershire at their time of primary care registration. We examined the temporal relationship between dates of Flag-4 primary care registration $(n=59007)$ and foreign-born TB (FB-TB) cases $(n=857)$, for immigrants arriving to the UK after 1999. TB diagnosed $>6$ months after registration was considered potentially preventable with screening. Primary outcomes were the potentially preventable proportion of FB-TB and the number needed to screen (NNS) of immigrants to identify one potentially preventable case, stratified by age and region of origin. Results 250 cases (29\%) were potentially preventable in Flag-4-registered immigrants. Overall, 511 cases $(60 \%)$ were potentially preventable among primary-care registered immigrants, implying a significant proportion without Flag-4 status. Prospective TB incidence $(95 \% \mathrm{Cl})$ after Flag-4 registration was 183 (163 to 205) cases/ 100000 person-years, with a NNS $(95 \% \mathrm{Cl})$ of 145 (130 to 162). Targeted screening was most effective for 16-35 year olds from TB incidence regions 150-499/ 100000 (NNS $(95 \% \mathrm{Cl})=65$ (57 to 74), preventing 159 (18.7\%) cases). Unpreventable TB risk increased with delayed primary care registration after UK entry $(p<0.001)$ and was associated with HIV seropositivity (relative risk $(95 \% \mathrm{Cl})=1.89$ (1.25 to 2.84$), \mathrm{p}=0.003$ ).

Conclusions LTBI screening at primary care registration offers an effective strategy for potentially identifying immigrants at high risk of developing TB.

\section{INTRODUCTION}

The incidence of tuberculosis (TB) in the UK has risen significantly over the past decade despite broad implementation of established practices for disease control. ${ }^{1}$ This trend has been associated with a growing proportion of disease in foreignborn residents from TB-endemic countries, arising primarily from reactivation of latent infection with Mycobacterium tuberculosis (LTBI) acquired in the country of origin. ${ }^{2}$ Targeted screening and

\section{Key messages}

What is the key question?

- What is the potential impact on prospective tuberculosis (TB) incidence of implementing a strategy of targeted latent TB infection (LTBI) screening at the time of immigrant registration with primary care?

\section{What is the bottom line?}

- A policy of immigrant screening for LTBI at the time of primary care registration identified up to $60 \%$ of potentially preventable foreign-born TB cases and was heterogeneous across different immigrant groups.

\section{Why read on?}

- This study provides evidence for the strengths and limitations of initiating LTBI screening at the time of primary care registration in a UK TB hotspot.

treatment of new arrivals with LTBI may therefore significantly lower prospective $\mathrm{TB}$ incidence and is widely considered a key element of the successful multi-faceted TB prevention strategy implemented by the USA. ${ }^{3}$

There is recent evidence that targeted screening of high-risk immigrants may be delivered cost effectively at a threshold that would have greatest impact on the prospective incidence of $\mathrm{TB}$ in the UK. ${ }^{4}$ Although the National Institute for Health and Clinical Excellence recommends LTBI screening in recent immigrants, there is little guidance on approaches for implementation. ${ }^{5}{ }^{6}$ Effective TB prevention will require LTBI screening programmes to incorporate strategies that will reliably identify a large proportion of immigrants at significant prospective risk of $\mathrm{TB}$, sufficiently in advance of disease onset to alter the natural history of progression. ${ }^{7}$ This poses a significant challenge as the UK does not operate a comprehensive system for registering immigrants at their time of UK entry. A model using immigrant registrations with primary care to identify eligible groups for LTBI screening is attractive as this most often represents the first interaction of immigrants with the health 
sector; there is evidence that good uptake to primary care based TB-related screening programmes can be achieved with appropriate educational interventions; and general practitioners are supportive of primary care based screening. ${ }^{8}$

All individuals registered with primary care in England and Wales appear on the NHS patient registration data system (PRDS). This is a central platform that collects registration data entered at each primary care practice. The PRDS includes a specific code (Flag-4) that is assigned to the first registration episode with primary care for individuals having either a previous address outside the UK or residence abroad of greater than 3 months. ${ }^{9}$ As a resource for identifying immigrants, the scope and utility of the PRDS, and in particular the Flag-4 subset of the registry, is presently unknown but merits evaluation.

In this 11-year retrospective cohort study, we examined the temporal relationship between Flag-4 primary care registration and $\mathrm{TB}$ notifications in predefined foreign-born cohorts gathered from local registers in a high TB burden region of England. We evaluated the effectiveness of Flag-4 registration as a resource to identify high-risk immigrants for LTBI screening by determining the prospective TB risk in healthy immigrants after Flag-4 registration and the proportion of $\mathrm{TB}$ occurring in foreign-born people that may be potentially prevented with screening implemented at or near the time of primary care registration.

\section{METHODS}

\section{Cohorts for study}

Cohorts for the study were all recorded foreign-born TB (FB-TB) notifications and Flag-4 immigrant registrations to Leicestershire between 1 January 2000 and 31 December 2010, with a UK arrival date after 31 December 1999. Leicestershire has a population of approximately 1 million, with $80 \%$ of all $\mathrm{TB}$ cases occurring in foreign-born people, representative of the demographic profile of TB in the UK. ${ }^{1}$ The region includes Leicester City where $80 \%$ of all cases occur. The proportion of foreign-born residents in the City is $36 \%$ (national average $13 \%$ ) and $\mathrm{TB}$ incidence is high (58 per 100000 population). ${ }^{10} 11$ Population growth for the City is driven by net inflow of international migrants, with more than 50\% arriving from countries outside the European Union. ${ }^{12}$ Annual migration away from the region is estimated at $5.3 \% .^{13}$

Clinical and demographic data for all FB-TB notifications were obtained from the local networked electronic TB database, a locally designed notification database established in 2006 that requires mandatory completion prior to commencing $\mathrm{TB}$ treatment.

Flag-4 immigrant registration data were gathered from the Leicestershire NHS PRDS. The NHS number, a unique personspecific identifier common to both datasets, was used to amalgamate data between the cohorts.

\section{Definitions and assumptions}

FB-TB cases were categorised as either captured or missed by cross referencing their NHS number to the Flag-4 registry. For FB-TB cases that were missed, further evidence for primary care registration was sought from the full Leicestershire NHS PRDS. On this basis, FB-TB cases were classified as either registered or unregistered with primary care. For cases with non Flag-4 primary care registration, the date of registration was obtained from the PRDS.

For PRDS registered cases (Flag-4 or non-Flag-4), we postulated only notifications occurring at least 6 months after registration were potentially preventable with screening. This interval assumed entry to screening at or shortly after primary care registration and incorporated a 2 -month period for early active disease to clinically manifest, ${ }^{14}$ and a further 4 -month period to initiate screening and deliver maximum efficacy with a 3 -month chemoprevention regimen of rifampicin/isoniazid. ${ }^{5} 15$ FB-TB that was not preventable was subclassified as unpreventable in cases without evidence of PRDS registration at the time of TB notification, and modifiable if notification occurred less than 6 months after registration, as screening would still have a role in TB prevention (with partial efficacy) and early identification of active disease.

\section{Study outcomes}

Primary outcomes

The study had two prespecified coprimary outcomes to determine effectiveness of the Flag-4 registry: the proportion of all FB-TB cases that were potentially preventable using the Flag-4 registry; and the number needed to screen (NNS) of immigrants at the time of Flag-4 registration to identify one potentially preventable case.

Further stratified analysis was performed to inform targeted screening in prespecified subgroups of age at primary care registration (children (aged <16 years), young adults (aged 1635 years) and older adults (aged $36+$ years)) and WHO TB incidence in country of origin (low to moderate $=<150 / 100000$; high $=150-499 / 100000$; and very high $=\geq 500 / 100000)$, on the basis of reported UK screening thresholds. ${ }^{4}$

\section{Secondary outcomes}

For the FB-TB cohort, factors associated with first having Flag-4 coded primary care registration, and having preventable disease if registered with the Flag-4 code were examined as independent secondary outcomes using multivariable binary logistic regression analysis (see statistical analysis).

A third secondary outcome was the proportion of preventable FB-TB that was represented by the Flag- 4 subset of the PRDS. This was quantified as the rate ratio (RR) of preventable TB identified with Flag-4, as a proportion of all such cases in PRDS-registered immigrants of the FB-TB cohort. Stratified analysis was performed for this outcome in the prespecified subgroups for targeted screening of age at primary care registration and TB incidence in country of origin as described earlier.

\section{Statistical analysis}

Between-group comparisons of proportions, parameteric and non-parametric distributions were performed using the $\chi^{2}$ test, Kruksal-Wallis test and analysis of variance as indicated for specific variables presented in the results (tables 1 and 3). TB incidence rates and risk estimates were calculated in the Flag-4 registered population, without a diagnosis of $\mathrm{TB}$ at or prior to their date of primary care registration. Incidence rates were defined assuming a Poisson distribution as the number of cases occurring over an observation period of 100000 patient-years, with 95\% CIs computed using the Byar approximation. ${ }^{16}$ Five-year cumulative TB risk was computed using Kaplan-Meier survival analysis. Cox proportional hazards multivariable regression was performed to examine and compare TB risk across subgroups for targeted screening, of age at primary care registration and WHO TB incidence in country of origin, as previously described. Outcomes are expressed as HRs (adjusted HRs) that are adjusted for these variable groups. Validity of the proportional hazards assumption was tested by examining the slope of the regression line of Schoenfeld residuals against time and ensuring this was zero. ${ }^{17}$ 
The NNS was calculated as the reciprocal of TB risk ${ }^{18}$ in Flag-4 registered immigrants who remained healthy or developed TB $\geq 6$ months after primary care registration.

Factors associated with the secondary endpoints of having Flag-4 coded primary care registration and having preventable disease if registered with the Flag-4 code were examined using multivariable logistic regression analysis. Variables included for both analyses were gender; age group at primary care registration; disease type (non-pulmonary, pulmonary smear positive and pulmonary smear negative); and WHO TB incidence in country of origin. As preventable TB was dependent on primary care registration occurring prior to disease onset, we also included the interval between UK entry and primary care registration, expressed in months, as a continuous variable in the analysis of factors associated with preventable disease. Other potential available data fields (table 1) were excluded on the basis of either multi-collinearity with one of the included variables or, in the case of HIV status, non-random missing data. The model was constructed entering all the stated variables (the enter method). Associations for each variable group were expressed as ORs (adjusted ORs), adjusted for the other input variables in the model, with $95 \%$ CIs. Statistical significance was computed from Wald statistics. A backward stepwise algorithm was applied using the same variables with a retention threshold at the $5 \%$ significance level to validate significant associations using the enter method. The predictive performance of each regression model was quantified using Somers' D and the c-statistic.

For all analyses, $\mathrm{p}<0.05$ was taken as the threshold of statistical significance. TB incidence rates $(95 \%$ CIs) were calculated using open access software. ${ }^{19}$ Schoenfeld residuals were computed using SAS V.9.4 (SAS Institute Inc, Cary, North Carolina, USA). All remaining statistical analyses were performed with SPSS V.16 (SPSS, Inc, Chicago, Illinois, USA) and Prism V.5 (GraphPad Software, San Diego, California, USA).

\section{RESULTS}

\section{Characteristics of the study cohorts}

The cohorts are summarised in table 1. In total, 71857 new immigrant Flag-4 registrations were recorded between January 2000 and December 2010 from 148 primary care practices in Leicestershire (figure 1). For 59007 registrations, a UK entry date after 1999 was established and formed our registration cohort. A total of $28438(48 \%)$ registrations arrived from countries with a reported WHO TB incidence of $\geq 150 / 100000$. Overall, 18892 registrations (32\%) were in people arriving from the Indian subcontinent (ISC) and this group comprised $66.4 \%$ of all immigrants from higher $(\geq 150 / 100000)$ TB incidence countries. The median time to Flag-4 primary care registration after UK entry was 181 (IQR 25-950) days but was significantly longer for immigrants arriving from very high incidence countries (619 (IQR 90-1183) days, $\mathrm{p}<0.001$; table 1). Missing and inconsistent data for one or both of the mandatory data fields, date of UK entry and country of origin excluded 4293 (6.0\%) registration entries from the study. In 93\% $(n=3990)$ of subjects with missing data, the date of UK entry field was incomplete or unreliable. A higher proportion of missing data was identified for practices with the most Flag-4 registrations over the study period. For the top 10 practices by registration, contributing 15356 entries (23.4\%) on the registry, $7.8 \%$ of subjects were excluded for missing data compared with $5.8 \%$ for the remainder $(p<0.001)$. We also identified significant variability in the proportion of missing data between practices within this group (range 5.2-15.9\%; $\mathrm{p}<0.001$ ).
Over the same period, 1956 of 2413 TB notifications $(81.1 \%)$ occurred in foreign-born people (figure 1). Of those with a recorded year of UK entry, 857 (50\%) arrived after 1999 (figure 1 and table 1) and constituted the FB-TB cohort. Nine of 621 FB-TB cases (1.4\%) identified on the Flag-4 registry had missing UK entry data and were excluded; 458 cases were identified with a UK entry date after 31 December 1999.

A proportion of $93.7 \%$ of all FB-TB cases arose in people arriving from countries with $\mathrm{TB}$ incidence $\geq 150 / 100000$ and $66.5 \%$ of all FB-TB cases occurred in young adults aged between 16 and 35 years. HIV testing was performed in 624 $(72.8 \%)$ cases and $84(13.4 \%)$ positive results were identified. Testing was performed more frequently in immigrants from very high incidence countries and $65 \%$ of tested patients had HIV coinfection, accounting for $67 \%$ of all HIV-associated FB-TB in the study cohort (table 1).

\section{FB-TB and history of primary care registration}

Overall, 810 (94.5\%) FB-TB cases were registered on the PRDS and 458 cases $(53.4 \%)$ were captured on the Flag- 4 registry. For this subgroup, the median (IQR) time to TB after UK entry was 911 (557-1597) days. Sixty-seven cases (14.6\%) were notified within 12 months of arrival. The interval to Flag-4 primary care registration after UK entry in those developing TB was significantly longer than for Flag-4 registered immigrants overall (median (IQR) 541 (42-1654) days, p<0.001; (table 1)), with a consistent trend for longer delays in immigrants from very high incidence countries (table 1).

In the FB-TB cohort, multivariable analysis identified age group at primary care registration and WHO TB incidence in country of origin to be independently associated with Flag-4 status. A Flag- 4 code was less likely to have been assigned for primary care registrations in children and immigrants arriving from very high incidence countries (table 2).

\section{Preventable proportion of FB-TB and reliability of the Flag-4} code in subgroups for targeted screening

According to our definition, 29.2\% of all FB-TB cases $(n=250)$ may have been preventable with screening, using the Flag-4 registry alone. This proportion increased to $59.6 \%(n=511)$ if all primary care registrations (Flag-4 and non Flag-4) were considered (figure 1) (RR (95\% CI) of preventable TB identified with Flag-4 as a proportion of preventable cases on the PRDS $=0.49(0.43$ to $0.55), \mathrm{p}<0.001$; (table 3 )). The RR varied across subgroups and was considerably lower for immigrants from countries with TB incidence $<150 / 100000(\mathrm{RR}(95 \% \mathrm{CI})=0.32(0.17$ to 0.62$))$ and $\geq 500 / 100000(\mathrm{RR}(95 \% \mathrm{CI})=0.33(0.19$ to 0,64$))$; and children $(\mathrm{RR}(95 \% \mathrm{CI})=0.38(0.24$ to 0.58$))($ table 3$)$.

\section{Characteristics of unpreventable TB}

Overall, 232 FB-TB cases (27.1\%) were defined unpreventable as no record of primary care registration existed on the PRDS at the time of disease notification. For a further 114 FB-TB cases $(13.3 \%)$, disease was potentially modifiable with screening at primary care registration (figure 1).

In the cohort of Flag-4 registered FB-TB, 162 cases (35.4\%) were unpreventable. The interval to primary care registration after UK entry was the only independent factor associated with this outcome, with the odds increasing 1.03 fold (95\% CI 1.02 to 1.03$)$ for every month that primary care registration was delayed ( $\mathrm{p}<0.001$; table 2$)$.

HIV seropositivity was associated with a significantly higher proportion of unpreventable TB in the FB-TB subgroup that were HIV tested (19\% vs 10\%; unadjusted RR $(95 \% \mathrm{CI})=1.89$ 
Table 1 Characteristics of study cohorts: Leicestershire Flag-4 registered immigrants and foreign-born tuberculosis (TB) cases

\begin{tabular}{|c|c|c|c|c|c|}
\hline & \multirow[b]{2}{*}{ Overall } & \multicolumn{4}{|c|}{ WHO TB incidence per 100000 population } \\
\hline & & $<150$ & $150-499$ & $\geq 500$ & Sig $^{*}$ ( $p$-value) \\
\hline \multicolumn{6}{|l|}{ Flag-4 registered immigrants } \\
\hline $\mathrm{N}$ registrations (\% of total) & 59007 & $30569(51.8)$ & $25800(43.7)$ & $2638(4.5)$ & - \\
\hline \multicolumn{6}{|l|}{ Gender } \\
\hline Male $(\%)$ & $30752(52)$ & $15387(50)$ & $14025(54)$ & $1340(51)$ & $<0.001^{*}$ \\
\hline \multicolumn{6}{|l|}{ Age at primary care registration } \\
\hline$<16$ years $(\%)$ & $10515(18)$ & $6327(21)$ & $3474(14)$ & $714(27)$ & $<0.001 *$ \\
\hline $16-35$ years $(\%)$ & $37323(63)$ & $20297(66)$ & $15813(61)$ & $1213(46)$ & \\
\hline$\geq 36$ years $(\%)$ & $11169(19)$ & $3945(13)$ & $6513(25)$ & $711(27)$ & \\
\hline Ranked top 5 countries of origin & $\begin{array}{l}\text { India } \\
\text { Poland } \\
\text { China } \\
\text { Zimbabwe } \\
\text { Somalia }\end{array}$ & $\begin{array}{l}\text { Poland } \\
\text { China } \\
\text { Slovakia } \\
\text { France } \\
\text { Germany }\end{array}$ & $\begin{array}{l}\text { India } \\
\text { Somalia } \\
\text { Pakistan } \\
\text { Nigeria } \\
\text { Bangladesh }\end{array}$ & $\begin{array}{l}\text { Zimbabwe } \\
\text { South Africa } \\
\text { Sierra Leone } \\
\text { Botswana } \\
\text { Swaziland }\end{array}$ & - \\
\hline Mean age UK entry, years (SD) & $25.0( \pm 13.4)$ & $22.7( \pm 11.9)$ & $27.8( \pm 14.3)$ & $24.4( \pm 14.9)$ & $<0.001 \dagger$ \\
\hline Interval UK entry to registration, median days (IQR) & $181(25-950)$ & $164(26-787)$ & $176(22-1090)$ & $619(90-1883)$ & $<0.001 \ddagger$ \\
\hline \multicolumn{6}{|l|}{ Foreign-born TB cases } \\
\hline $\mathrm{N}$ cases (\% of total) & 857 & $54(6.3)$ & $711(83.0)$ & $92(10.7)$ & $<0.001$ \\
\hline \multicolumn{6}{|l|}{ Gender } \\
\hline Male $(\%)$ & $429(50)$ & $24(44)$ & $364(51)$ & $41(45)$ & $<0.001^{*}$ \\
\hline \multicolumn{6}{|l|}{ WHO geographical region } \\
\hline African (\%) & $186(21)$ & $4(8)$ & $90(12)$ & $92(100)$ & $<0.001^{*}$ \\
\hline Eastern Mediterranean (\%) & $145(17)$ & $11(20)$ & $134(19)$ & 0 & \\
\hline European $(\%)$ & $15(2)$ & $15(28)$ & 0 & 0 & \\
\hline SE Asia (\%) & $486(57)$ & $13(24)$ & $473(67)$ & 0 & \\
\hline West Pacific (\%) & $24(3)$ & $11(20)$ & $13(2)$ & 0 & \\
\hline \multicolumn{6}{|l|}{ Ethnic group } \\
\hline Indian subcontinent (\%) & $498(58)$ & $6(11)$ & $489(69)$ & $3(3)$ & $<0.001^{*}$ \\
\hline Black $(\%)$ & $224(26)$ & $14(26)$ & $130(18)$ & $80(87)$ & \\
\hline White (\%) & $128(15)$ & $4(7)$ & $2(<1)$ & 0 & \\
\hline Other (\%) & $6(1)$ & $30(56)$ & $89(13)$ & $9(10)$ & \\
\hline \multicolumn{6}{|l|}{ Age at primary care registration (\%)§ } \\
\hline$<16$ years $(\%)$ & $48(6)$ & $7(15)$ & $30(4)$ & $11(13)$ & $<0.001 *$ \\
\hline $16-35$ years $(\%)$ & $542(67)$ & $33(69)$ & $460(68)$ & $49(56)$ & \\
\hline$\geq 36$ years $(\%)$ & $220(27)$ & $8(16)$ & $185(28)$ & $27(31)$ & \\
\hline Interval from UK entry to registration, median days (IQR)ף & $541(42-1654)$ & $283(20-1082)$ & $509(32-1603)$ & $1534(292-2285)$ & $<0.001 \ddagger$ \\
\hline \multicolumn{6}{|l|}{ Age at TB diagnosis } \\
\hline$<16$ years $(\%)$ & $27(3)$ & $5(9)$ & $15(2)$ & $7(8)$ & $0.004^{*}$ \\
\hline $16-35$ years (\%) & $570(67)$ & $36(67)$ & $476(67)$ & $58(63)$ & \\
\hline$\geq 36$ years $(\%)$ & $259(30)$ & $13(24)$ & $219(31)$ & $27(29)$ & \\
\hline \multicolumn{6}{|l|}{ Disease type } \\
\hline Non-pulmonary (\%) & $496(58)$ & $26(48)$ & $427(60)$ & $43(47)$ & $0.035^{*}$ \\
\hline Pulmonary smear positive (\%) & $103(12)$ & $11(20)$ & $78(11)$ & $14(15)$ & \\
\hline Pulmonary smear negative (\%) & $257(30)$ & $17(32)$ & $205(29)$ & $35(38)$ & \\
\hline \multicolumn{6}{|l|}{ HIV result } \\
\hline Positive $(\%)^{* *}$ & $84(13)$ & $3(8)$ & $25(5)$ & $56(65)$ & $<0.0001^{*}$ \\
\hline Unknown (\%)†† & $233(27)$ & $16(30)$ & $211(30)$ & $6(7)$ & \\
\hline
\end{tabular}

(1.25 to 2.84), $\mathrm{p}=0.003)$. Compared with patients who were HIV negative, time to Flag-4 primary care registration after UK entry was longer (median (IQR) $=1515$ (555-2202) days vs 415 (36-1558) days; $\mathrm{p}<0.005)$ and time to disease notification shorter (median $(\mathrm{IQR})=587$ (208-1182) days vs 1163 (669$1854)$ days; $p<0.005)$ for patients who were HIV positive.
Prospective TB risk and effectiveness of the Flag-4 registry for screening

Healthy immigrants without a diagnosis of $\mathrm{TB}$ at the time of Flag-4 registration were observed for a median (IQR) period of 764 (311 to 1541 ) days after registration, with a cumulative cohort observation period of 161461 person-years (table 4). 


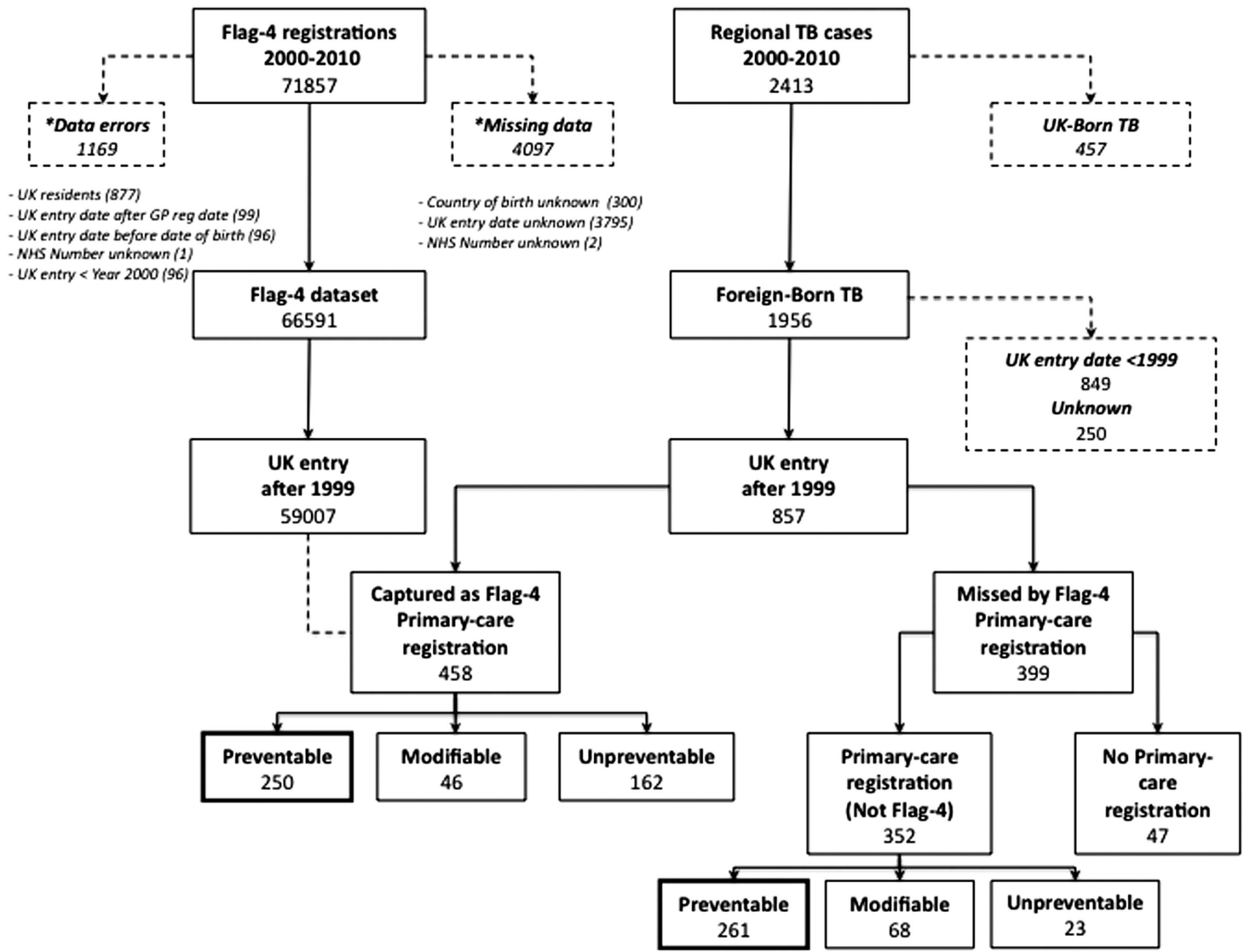

Figure 1 Study overview: cohorts extracted for study. Dashed arrows indicate groups excluded from further analysis due to data errors or missing information (see Methods).

Table 2 Multivariable logistic regression analysis of factors associated with Flag-4 registration and unpreventable tuberculosis (TB) if Flag-4 registered

\begin{tabular}{|c|c|c|c|c|c|c|}
\hline \multirow[b]{2}{*}{ Variables } & \multicolumn{3}{|c|}{ Flag-4 status if registered with primary care* } & \multicolumn{3}{|c|}{ Unpreventable TB with Flag-4 registrationt } \\
\hline & n & AOR $(95 \% \mathrm{Cl}) \ddagger$ & Sig $\ddagger$ & n & AOR $(95 \% \mathrm{CI}) \ddagger$ & Sig $\neq$ \\
\hline Gender & & & 0.075 & & 0.803 & \\
\hline Male§ & 212/395 & 1.0 & - & $94 / 212$ & 1.0 & - \\
\hline Female & $246 / 415$ & $1.30(0.98-1.72)$ & 0.075 & $114 / 246$ & $1.07(0.64-1.80)$ & 0.803 \\
\hline Age at primary care registration & & & 0.026 & & & 0.196 \\
\hline$<16$ years§ & $17 / 48$ & 1.0 & - & $2 / 17$ & 1.0 & - \\
\hline $16-35$ years & $307 / 542$ & $2.32(1.22-4.40)$ & 0.043 & $132 / 307$ & $8.88(0.81-96.8)$ & 0.071 \\
\hline$>35$ years & $134 / 220$ & $2.48(1.27-4.83)$ & 0.021 & 74/134 & $9.29(0.81-106)$ & 0.070 \\
\hline WHO TB incidence region & & & 0.001 & & & 0.063 \\
\hline$\geq 500 / 10^{6} \S$ & $38 / 87$ & 1.0 & - & $24 / 38$ & 1.0 & - \\
\hline $150-499 / 10^{6}$ & $402 / 675$ & $2.41(1.30-4.45)$ & $<0.001$ & $175 / 402$ & $1.31(0.41-4.15)$ & 0.190 \\
\hline$<150 / 10^{6}$ & $18 / 48$ & $0.77(0.37-1.60)$ & 0.505 & $9 / 18$ & $5.29(1.03-27.1)$ & 0.022 \\
\hline Disease type & & & 0.722 & & & 0.182 \\
\hline Non-pulmonary§ & $271 / 480$ & 1.0 & - & $124 / 271$ & 1.0 & - \\
\hline Pulmonary smear negative & $136 / 237$ & $1.14(0.83-1.58)$ & 0.577 & $58 / 136$ & $1.62(0.90-2.94)$ & 0.112 \\
\hline Pulmonary smear positive & $51 / 93$ & $1.07(0.67-1.70)$ & 0.999 & $26 / 51$ & $1.81(0.73-4.46)$ & 0.197 \\
\hline Interval between UK entry and GP registration, months & - & - & - & - & $1.03(1.02-1.03)$ & $<0.001$ \\
\hline
\end{tabular}


Table 3 The preventable proportion of TB according to primary care registration status

\begin{tabular}{|c|c|c|c|c|}
\hline$\%$ Preventable FB-TB cases ( $\mathrm{N}$ preventable/N total) & Flag-4 registration & Primary care registration (PRDS) & $\mathrm{RR}^{*}(95 \% \mathrm{Cl})$ & Sig (p-value) $\dagger$ \\
\hline Overall & $29.1(250 / 857)$ & $59.6(511 / 857)$ & $0.49(0.43$ to 0.55$)$ & $<0.0001$ \\
\hline \multicolumn{5}{|l|}{ WHO TB incidence in country of origin/100 000} \\
\hline$<150$ & $16.7(9 / 54)$ & $51.9(28 / 54)$ & $0.32(0.17-0.62)$ & 0.0002 \\
\hline 150-499 & $31.9(227 / 711)$ & $61.9(440 / 711)$ & 0.52 (0.46 to 0.58$)$ & $<0.0001$ \\
\hline $500+$ & $15.2(14 / 92)$ & $46.7(43 / 92)$ & 0.33 (0.19 to 0.64$)$ & $<0.0001$ \\
\hline \multicolumn{5}{|l|}{ Age at primary care registration } \\
\hline$<16$ years & $31.2(15 / 48)$ & $83.3(40 / 48)$ & $0.38(0.24$ to 0.58$)$ & $<0.0001$ \\
\hline $16-35$ years & $32.3(175 / 542)$ & $63.7(345 / 542)$ & 0.51 (0.44 to 0.58 ) & $<0.0001$ \\
\hline$>35$ years & $27.3(60 / 220)$ & $57.3(126 / 220)$ & $0.48(0.37$ to 0.61$)$ & $<0.0001$ \\
\hline
\end{tabular}

The preventable proportion was calculated in subgroups of the foreign-born (FB)-TB cohort, stratified according to WHO TB incidence region of origin and age at primary care registration.

${ }^{*} \mathrm{RR}$, rate ratio of the preventable proportion of TB in Flag-4 registered immigrants as a fraction of the total preventable proportion in our FB-TB cohort. A higher RR indicates greater representation of primary care registered preventable cases on the Flag- 4 registry.

†Statistical significance measured for differences between Flag-4 registration and NHS patient registration data system (PRDS) registration using $\chi^{2}$ test for proportions.

‡This subgroup analysis was confined to foreign-born TB with primary care registration $(\mathrm{N}=810)$.

Based on published migratory statistics, we estimate $5.3 \%$ attrition of our cohort over the median period of observation. ${ }^{13}$ The median (IQR) time to TB after Flag-4 registration was 712 (352-1317) days and this was similar to the interval to TB in non-Flag-4 registered immigrants (median $(\mathrm{IQR})=716 \quad(279-$ $1395)$ days). The overall $\mathrm{TB}$ incidence rate $(95 \% \mathrm{CI})$ after Flag-4 registration was 183 (163 to 205)/100 000 person years, with a 5 -year cumulative TB risk of $0.75 \%(95 \%$ CI $0.69 \%$ to $0.83 \%$ ) (table 4). Subgroups stratified respectively by age at primary care registration and TB incidence in the country of origin were independently associated with prospective TB risk (figure 2, table 4), being highest for adults ( $>16$ years) and immigrants from countries with incidence 150-499/100 000 (table 4).

Using a policy of unselected screening, 145 (95\% CI 130 to 162) Flag-4 registering immigrants would need to be screened to identify one preventable case of $\mathrm{TB}$ at 5 years. Targeted screening was most effective in young adults (16-35 years) from high-incidence countries. Screening of this subgroup could have prevented $18.6 \%$ of FB-TB cases in our cohort with a NNS of 65 (95\% CI 57 to 74$)$ (table 5).

\section{DISCUSSION}

Strengths and limitations of the study

Although there is an increasing body of evidence to support the cost effectiveness and impact of specific LTBI screening algorithms, effectiveness in practice is critically dependent on the efficiency of strategies for identifying target groups. Our study focused on this aspect of implementation by examining the effectiveness of identifying at-risk immigrants at their time of primary care registration in a high TB incidence UK region. We quantified effectiveness as the NNS to prevent one case of TB. This analysis took into account TB risk in the registering population and included consideration of the temporal relationship between registration and TB to determine whether screening could have prevented disease.

Biases exist due to exclusion of missing data, cohort attrition with internal migration away from the region during the observation period and possible under ascertainment of $\mathrm{TB}$ cases prior to 2006 when data records were more reliant on central registries.

There was considerable variability in the proportion of missing data for mandatory data fields used in the study. This

Table 4 Observed tuberculosis (TB) incidence and prospective TB risk in Flag-4 registered immigrants

\begin{tabular}{|c|c|c|c|c|c|c|c|}
\hline & $\begin{array}{l}\text { Observation } \\
\text { time/patient-years (TB events) }\end{array}$ & $\begin{array}{l}\text { Incidence rate } / 100000 \\
\text { patient-years }(95 \% \mathrm{Cl})\end{array}$ & $\begin{array}{l}\text { Incidence rate } \\
\text { ratio }(95 \% \mathrm{Cl})\end{array}$ & $\begin{array}{l}\text { Sig } \\
\text { ( } p \text { value) }\end{array}$ & $\begin{array}{l}\text { *5-year TB risk, } \\
\%(95 \% \mathrm{CI})\end{array}$ & $\begin{array}{l}\text { Adjusted hazard } \\
\text { ratiot }(95 \% \mathrm{Cl})\end{array}$ & $\begin{array}{l}\text { Sig } \\
\text { ( } p \text { value) }\end{array}$ \\
\hline All & $161461(296)$ & 183.3 (163.0 to 205.4$)$ & - & - & 0.75 (0.69 to 0.83$)$ & - & - \\
\hline \multicolumn{8}{|c|}{ Age group at primary care registration } \\
\hline $16-35 \ddagger$ & $94612(208)$ & 219.8 (191.0 to 251.8$)$ & 1 & - & $0.90(0.80$ to 1.0$)$ & 1 & - \\
\hline$<16$ & 33030 (15) & 45.4 (25.4 to 74.9$)$ & $0.21(0.12$ to 0.35$)$ & $<0.001$ & $0.21(0.14$ to 0.33$)$ & 0.25 (0.15 to 0.42$)$ & $<0.001$ \\
\hline $36+$ & $33819(73)$ & $215.9(169.2$ to 271.4$)$ & $0.98(0.75$ to 1.28$)$ & 0.901 & $0.89(0.72$ to 1.08$)$ & $0.77(0.59$ to 1.01$)$ & 0.061 \\
\hline \multicolumn{8}{|c|}{ WHO TB incidence region/100 000 population } \\
\hline $150-499 \ddagger$ & $79460(269)$ & 338.5 (299.3 to 381.5$)$ & 1 & - & 1.40 (1.26 to 1.55$)$ & 1 & - \\
\hline$<150$ & $72617(11)$ & 15.1 (7.6 to 27.1$)$ & $0.04(0.02$ to 0.08$)$ & $<0.001$ & $0.07(0.04$ to 0.10$)$ & $0.04(0.02$ to 0.08$)$ & $<0.001$ \\
\hline $500+$ & $9384(16)$ & 170.5 (97.4 to 276.9$)$ & $0.50(0.30$ to 0.83$)$ & 0.005 & 0.91 (0.59 to 1.37$)$ & $0.58(0.35$ to 0.96$)$ & 0.030 \\
\hline
\end{tabular}




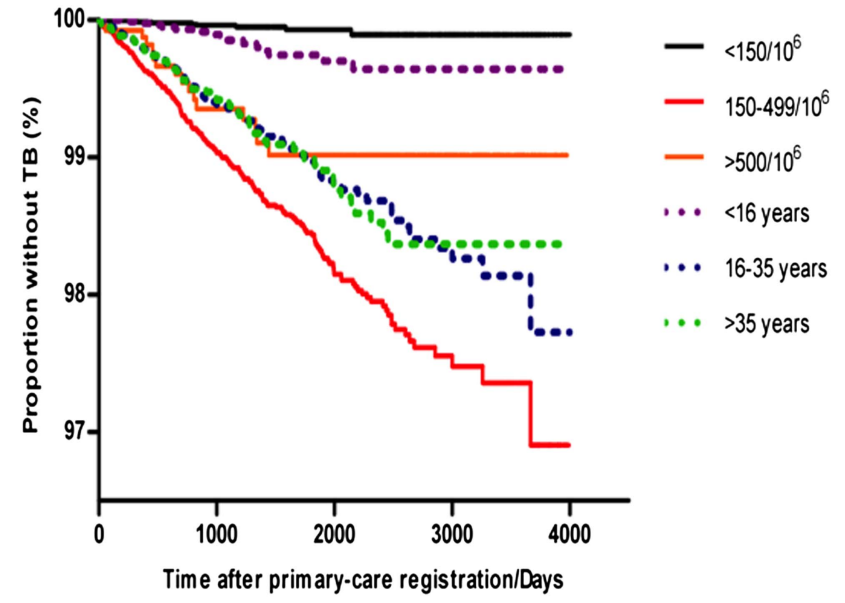

Figure 2 Prospective tuberculosis (TB) risk with time after Flag-4 registration. Kaplan-Meier plot presenting the proportion of the population without a diagnosis of TB at or prior to Flag-4 registration that remain disease free, stratified by WHO TB incidence region of origin and age at Flag-4 primary care registration.

has implications for implementing screening in practice as the same fields inform screening eligibility. Data are entered manually and primarily by administrative staff at individual practices. Missing data was identified in a higher proportion of registrations at practices with a larger Flag-4 registering population, suggesting an association with administrative burden. However, there was evidence of significant variability between these practices, suggesting that differences in the quality and reliability of data entry exist independent of this burden. Effective implementation of screening in primary care will require improvements in systems for data management. In contrast to the Flag-4 registry, a considerably smaller proportion of missing data was identified for captured FB-TB cases. As a consequence of this discordance, it is possible that our results overestimate TB risk, NNS and the proportion of potentially preventable TB cases on the Flag-4 registry.
Overall, the effects of the confounders described are likely to be small and given the size of the cohorts studied and the duration of follow-up, are unlikely to have significantly affected our findings. We are mindful that our study was confined to the catchment population of Leicestershire and broader application of the findings will require further study in other high $\mathrm{TB}$ burden regions of the UK. Outside Greater London, these are typically inner city regions, housing a large proportion of commonwealth migrants and comparable to the cohort we have presented. ${ }^{20}$

\section{Principal findings}

We found up to $60 \%$ of cases in our region were potentially preventable with LTBI screening initiated at the time of immigrant primary care registration. This figure represents a ceiling of effectiveness on the basis of the strict criteria we specified and implies that screening will be impactful but insufficient to eradicate TB. In practice, the effectiveness of screening to prevent TB will be determined by the completeness of screening coverage, uptake to and adherence with treatment, and the effectiveness of treatment in this group. Approximately 50\% of the potentially preventable FB-TB cases were identifiable using the Flag-4 code. Flag-4 was variably effective in different subgroups, being most reliable in immigrants from the ISC but approximately $50 \%$ less effective for identifying preventable FB-TB in immigrants arriving from very high incidence countries of sub-Saharan Africa. Prospective TB risk in the Flag-4 registered population was also significantly lower in this group compared with immigrants arriving from the ISC and other countries with a TB incidence of 150-500/100 000. This was an unexpected finding and suggests that the subgroup of black Africans with Flag-4 registration may not be representative of the population at highest risk of TB. This view is supported by a near twofold greater proportion with HIV seropositivity in black Africans not having Flag-4 registration at the time of TB diagnosis. This has clear implications for the utility of this screening model in a vulnerable group and further studies are needed to better understand the socio-demographic factors associated with this finding and strategies that may improve their identification sooner after UK arrival.

Table 5 Effectiveness of Flag-4 registration and targeted latent tuberculosis (TB) infection screening

\begin{tabular}{|c|c|c|c|c|c|c|}
\hline & & & \multicolumn{4}{|c|}{ Age groups at primary care registration } \\
\hline & & & All & $<16$ & $16-35$ & $36+$ \\
\hline \multirow[t]{10}{*}{$\begin{array}{l}\text { WHO TB incidence } \\
\text { region/100 } 000 \text { population }\end{array}$} & \multirow[t]{2}{*}{ All } & $\begin{array}{l}\mathrm{NNS}^{*}(95 \% \mathrm{Cl}) \\
(\mathrm{N} \text { (preventable cases)/N (cohort)) } \dagger\end{array}$ & $\begin{array}{l}145(130 \text { to } 162) \\
(250 / 49162)\end{array}$ & $\begin{array}{l}465(294 \text { to } 746) \\
(15 / 9063)\end{array}$ & $\begin{array}{l}121(107 \text { to } 137) \\
(175 / 30369)\end{array}$ & $\begin{array}{l}129(102 \text { to } 162) \\
(60 / 9730)\end{array}$ \\
\hline & & $\%$ Preventable cases $\ddagger$ & 29.2 & 1.8 & 20.4 & 7.0 \\
\hline & \multirow[t]{2}{*}{$<150$} & $\begin{array}{l}\text { NNS* }(95 \% \mathrm{Cl}) \\
(\mathrm{N} \text { (preventable cases)/N (cohort)) } \dagger\end{array}$ & $\begin{array}{l}1546 \text { (925 to } 2625) \\
(10 / 24326)\end{array}$ & $\begin{array}{l}5291(814 \text { to } 100000) \\
(1 / 5283)\end{array}$ & $\begin{array}{l}1003(600 \text { to } 1704) \\
(8 / 15729)\end{array}$ & No events \\
\hline & & $\%$ Preventable cases $\ddagger$ & 1.2 & 0.1 & 0.9 & \\
\hline & \multirow[t]{3}{*}{$150-499$} & NNSt $(95 \% \mathrm{Cl})$ & 80 (71 to 90$)$ & 345 (176 to 704$)$ & 65 (57 to 74$)$ & 82 (65 to 105$)$ \\
\hline & & (N (preventable cases)/N (cohort)) $\dagger$ & $(226 / 22510)$ & $(9 / 3137)$ & $(159 / 13569)$ & $(58 / 5804)$ \\
\hline & & $\%$ Preventable cases $\ddagger$ & 26.4 & 1.1 & 18.6 & 6.8 \\
\hline & \multirow[t]{3}{*}{$500+$} & NNS $^{*}(95 \% \mathrm{Cl})$ & 120 (76 to 193$)$ & 88 (42 to 197$)$ & 104 (56 to 203) & 513 (91 to 6536) \\
\hline & & (N (preventable cases)/N (cohort)) $\dagger$ & $(14 / 2326)$ & $(5 / 643)$ & $(8 / 1071)$ & $(1 / 612)$ \\
\hline & & $\%$ Preventable cases $\ddagger$ & 1.6 & 0.6 & 0.9 & 0.1 \\
\hline
\end{tabular}

The table presents effectiveness as the number needed to screen (NNS) - see below and Methods. Targeted screening is considered in subgroups stratified by age at primary care registration and WHO TB incidence in the country of origin.

${ }^{*}$ NNS, the number of registrations needed to be screened to identify one preventable case of foreign-born TB (95\% Cl) occurring within 5 years of Flag- 4 registration. This was computed as the reciprocal of cumulative 5-year TB risk derived from Kaplan-Meier survival analysis (see Methods).

†Absolute number of preventable cases ( $\mathrm{N}$ (preventable)) occurring in the observed cohort ( $\mathrm{N}$ (cohort)). $\mathrm{N}$ (cohort) was the total number of immigrants in each specified subgroup observed for $>6$ months after Flag-4 registration that remained disease free during this period.

$\ddagger$ Preventable cases expressed as the percentage of all foreign-born TB. This figure summarises the likely impact on local case load of an effective latent TB infection screening programme in each stated subgroup. 
Despite these limitations, our NNS estimates indicate that screening initiated at the time of Flag- 4 registration retains efficacy in all immigrant adults (aged $>16$ years) arriving from countries with a TB incidence $>150 / 100000$.

\section{Changes to coding of immigrant registrations with primary care} The Flag-4 code is solely assigned to the first registration with primary care after UK arrival. ${ }^{9}$ Thus, groups exhibiting higher rates of internal migration are more likely to be underrepresented. This would be in keeping with our observations of primary care registration without Flag- 4 status being identified more frequently in cases of preventable FB-TB among immigrants from very high incidence countries, a group reported to exhibit greater internal migration, ${ }^{21}$ and children, a group more likely to be registered with primary care soon after UK arrival and again following internal migration. One important implication is that LTBI screening initiated for immigrants already resident in the UK will be incomplete, using Flag-4 data alone. Prospectively, system changes are needed that support complete and accurate recording of country of origin and year of UK entry for all immigrant registration episodes, together with pathways developed to enable effective utilisation of this information for screening.

\section{Improving early primary care registration}

Over $40 \%$ of FB-TB cases in our cohort study were not preventable with screening implemented at the time of primary care registration. The principal reasons for this were failure to register with primary care prior to developing $\mathrm{TB}$ or not registering sufficiently in advance of the diagnosis for screening to have been effective. We found the delay to Flag-4 registration was almost threefold longer in immigrants progressing to TB, indicating that strategies to promote early registration are a necessary prerequisite for the success of this pathway. The problem was most apparent in immigrants from very high incidence countries with a median time to primary care registration that was over 20 months and threefold longer than for other immigrant groups. Longer delays to Flag-4 registration were coupled with earlier progression to TB, with HIV coinfection identified in two-thirds of tested cases. In this context, it may be pertinent to consider LTBI screening as one component of a broader remit that includes screening for coexisting chronic infections, particularly HIV and other blood borne viruses. ${ }^{22}$

A clear need exists to encourage primary care registration soon after UK arrival. Local engagement with third sector organisations will be important to promote education in vulnerable groups and to develop additional pathways to screening. These groups may engage with the healthcare system in other ways and the value of opportunistic screening should not be underestimated.

\section{CONCLUSIONS}

In summary, our data support the principle of immigrant LTBI screening at the time of primary care registration as a rational and effective strategy if implemented at a regional level in a high-burden setting. The majority of healthy migrants that go on to develop TB may be identified in this way, though differences are apparent between immigrant subgroups. The reasons for this are not clear but inter-regional differences in demographic composition of migrant communities may influence uptake to a primary care based model of screening. A multifaceted approach tailored to local need should therefore be encouraged.
Acknowledgements We thank Ashok Gadhia of the Leicester City PCT Health Informatics and Leicestershire NHS PRDS for extracting the Flag-4 data, Matthew Richardson (Statistician for the NIHR Leicester Biomedical Research Unit) for the statistical review and Professor Richard Baker (Director of NIHR CLAHRC-LNR) and the Leicestershire TB Management Board for their review and support of this study.

Contributors RKP collected and analysed the data on FB-TB cases from TBIT and the Flag-4 registry, undertook a literature search and wrote the first draft of the manuscript. $\mathrm{IB}$ and PM were involved in revising the manuscript. PH and GW jointly conceived the idea to undertake the retrospective cohort analysis and collected data on FB-TB cases as part of routine service provision. $\mathrm{PH}$ and GW were involved in revising the manuscript, analysing the data and providing advice on statistical methodology. RKP is a guarantor of the paper and accepts full responsibility for the work and the conduct of the study, had access to the data and controlled the decision to publish.

Funding This study was supported by the National Institute for Health Research (NIHR) Leicester Respiratory Biomedical Research Unit (BRU) and the NIHR Collaboration for Leadership in Applied Health Research and Care-Leicestershire, Northamptonshire and Rutland (NIHR CLAHRC for LNR). RKP was partly funded by the National Leadership Council.

Disclaimer The views expressed are those of the authors and not necessarily those of the NHS, the NIHR or the Department of Health.

Competing interests None.

Ethics approval The National Research Ethics Service (NRES) Committee East Midlands was consulted and a decision given that formal ethical review was not required.

Provenance and peer review Not commissioned; externally peer reviewed.

\section{REFERENCES}

1 Public Health England. Tuberuclosis in the UK 2013 report. London: Public Health England, August 2013. http://www.hpa.org.uk/webc/HPAwebFile/HPAweb_C/ 1317139689583 (accessed 4 Nov 2013).

2 Love J, Sonnenberg P, Glynn JR, et al. Molecular epidemiology of tuberculosis in England, 1988. Int J Tuberc Lung Dis 2009;13:201-7.

3 Liu Y, Weinberg MS, Ortega LS, et al. Overseas screening for tuberculosis in U. S.-bound immigrants and refugees. N Engl J Med 2009;360:2406-15.

4 Pareek M, Watson JP, Ormerod LP, et al. Screening of immigrants in the UK for imported latent tuberculosis: a multicentre cohort study and cost-effectiveness analysis. Lancet Infect Dis 2011;11:435-44.

5 National Institute for Health and Clinical Excellence. Tuberculosis-clinical diagnosis and management of tuberculosis, and measures for its prevention and control. London: National Institute for Health and Clinical Excellence, 2011. http://www. nice.org.uk/nicemedia/live/13422/53638/53638.pdf (accessed 4 Nov 2013).

6 Abubaker I, Lipman M, Anderson C, et al. Tuberculosis in the UK-time to regain control. BMJ 2011;343:d4281.

7 Cochrane AL, Holland WW. Validation of screening procedures. Br Med Bull 1971;27:3-8

8 Griffiths C, Sturdy P, Brewin P, et al. Educational outreach to promote screening for tuberculosis in primary care: a cluster randomised controlled trial. Lancet 2007;369:1528-34.

9 Office for National Statistics. Flag 4 GP registrations by local authority, mid 2009mid 2010. London: Office for National Statistics, 2011. http://www.ons.gov.uk/ons/ $\mathrm{rel} /$ migration 1/flag-4-gp-registrations-by-local-authority/mid-2009-mid-2010/index. html (accessed 4 Nov 2013).

10 NHS Leicester City and Leicester City Council. Leicester joint strategic needs assessment March 2012. Leicester City Council, 2012. http://www.leicester.gov.uk/ EasySiteWeb/GatewayLink.aspx?alld=97318" (accessed 4 Nov 2013).

11 Health Protection Agency. UK TB surveillance data: three-year average tuberculosis case reports and rates by local authority, England 2010-12. London: Health Protection Agency, 2013. http://www.hpa.org.uk/Topics/InfectiousDiseases/ InfectionsAZ/Tuberculosis/TBUKSurveillanceData/EnhancedTuberculosisSurveillance/ TBEnhanced03localarea/(accessed 4 Nov 2013).

12 Office for National Statistics. Population by nationality and country of birth, August 2012. London: Office for National Statistics, 2012. http://www.ons.gov.uk/ons/ taxonomy/index.html?nscl=Population+by+Nationality+and+Country+of+Birth (accessed 4 Nov 2013).

13 Office for National Statistics. Internal Migration by Local Authorities in England and Wales, Year ending June 2011. London: Office for National Statistics, 2012. http:/l www.ons.gov.uk/ons/dcp171778_280054.pdf (accessed 4 Nov 2013).

14 Verma R, Lee J, Haldar $\mathrm{P}$, et al. Impact of rapid access system for early referral of suspected TB cases. Thorax 2011;66(suppl):A90.

15 Girling DJ, Chan SL. A double-blind placebo-controlled clinical trial of three anti-tuberculosis chemoprophylaxis regimens in patients with silicosis in Hong Kong. Am Rev Respir Dis 1992;145:36-41.

16 Breslow NE, Day NE. Statistical methods in cancer research. Volume II-the design and analysis of cohort studies. IARC Sci Publ 1987:82:1-406. 
17 Schoenfeld D. Chi-squared goodness-of-fit tests for the proportional hazards regression model. Biometrika 1980;67:145-53.

18 Rembold CM. Number needed to screen: development of a statistic for disease screening. BMJ 1998;317:307-12.

19 Dean AG, Sullivan KM, Soe MM. OpenEpi: Open Source Epidemiologic Statistics for Public Health, Version 2.3.1. http://www.OpenEpi.com (accessed 4 Nov 2013).

20 Office for National Statistics. Internal migration by local authorities in England and Wales, year ending June 2012. Office for National Statistics, 2013. http://www.ons. gov.uk/ons/rel/migration1/internal-migration-by-local-authorities-in-england-andwales/year-ending-june-2012/stb-internal-migration-for-england-and-walesyear-ending-june-2012.html\#tab-Local-authority-level-moves (accessed 4 Nov 2013).

21 Raymer J, Smith PW, Giulietti C. Combining census and registration data to analyse ethnic migration patterns in England from 1991 to 2007. Popul Space Place 2011:17:73-88.

22 Lalvani A, Pareek M. Immigrant screening for TB: a missed opportunity to improve TB control in the United Kingdom. Pathog Glob Health 2012;106:5-7. 